\title{
First report of Meloidogyne hispanica in Iran
}

\author{
Ebrahim Shokoohi ${ }^{1} \cdot$ Zahra Parastar $^{2} \cdot$ Hadi Panahi $^{3} \cdot$ Shiva Abbaspour $^{2}$. \\ Hendrika Fourie $^{1} \cdot$ Mariette Marais $^{4}$
}

Received: 11 October 2015 /Accepted: 15 April 2016 / Published online: 29 April 2016

(C) Australasian Plant Pathology Society Inc. 2016

\begin{abstract}
Meloidogyne hispanica was identified morphologically, using perineal patterns, from root samples collected from a white mulberry growing in a park in Tehran, Iran. Molecular analysis was also undertaken, based on the D2D3 segment of the 28S rDNA region, and confirmed this population as $M$. hispanica. Phylogenetic analysis using the Bayesian inference method, places this population close to the same species from the Portugal (EU443608) and Spain (EU443606). This is the first record of M. hispanica in Iran.
\end{abstract}

Keywords Iran $\cdot$ White mulberry $\cdot$ Meloidogyne hispanica . Perineal pattern $\cdot 28 \mathrm{~S}$ rDNA

The genus Morus comprises many species (Suttie 2012). The species, Morus alba is one of the most popular Morus worldwide. This plant is widely cultivated as an ornamental plant in the parks in Iran. Meloidogyne species were recovered from root samples collected from stunted and cholorotic trees growing in "Azalia" park in Teheran.

\section{Ebrahim Shokoohi}

Ebrahim.Shokoohi@nwu.ac.za

1 Unit for Environmental Sciences and Management, North West University, Potchefstroom, South Africa

2 Plant Protection Clinic, District 15, Tehran Municipality, Tehran, Iran

3 Department of Plant Protection, College of Agriculture, Shahid Bahonar University of Kerman, Kerman, Iran

4 Nematology Unit, Biosystematic Division, Agricultural Research Council, Plant Protection Research Institute, (ARC-PPRI), Roodeplaat, Queenswood 0121, South Africa
During March 2015, root samples were collected from white mulberry in a park in Tehran (N: $35^{\circ} 37^{\prime} 51^{\prime \prime}$; E: $51^{\circ} 28^{\prime}$ $\left.25^{\prime \prime}\right)$. Roots were washed, cut in pieces and mature female specimens removed using a scalpel under a Nikon CH-2 stereo microscope. These specimens were fixed with a hot $4 \%$ formaldehyde solution and transferred to anhydrous glycerine using the method of De Grisse (1969). Characteristics of the perineal patterns as described by Hirschmann (1986) were used in identifying the Meloidogyne species (Fig. 1).

The molecular characterisation was based on the methodology used by Rashidifard et al. (2015). The original partial 28S (D2-D3 expansion) sequence of Meloidogyne hispanica is deposited in GenBank under accession number KT359553. Sequencing and Bayesian inference (BI) analysis of the ribosomal DNA region D2-D3 of 28S (Fig. 2) has been obtained for this species.

The sequence lengths flanked by the forward primer D2A (5"-ACAAGTACCGTGAGGGAAAGTTG-3") and the reverse primer D3B (5"-TCGGAAGGAACCAGCTACTA3") (according to Subbotin et al. 2006) of the 28S region of M. hispanica isolate are 694 base pairs long. The Blast test revealed that this population is seven base pairs different from the closest populations from Spain, Brazil and Portugal (EU443606, EU443607, EU443608; 98 \% identity respectively). Compared with the populations from Greece (KF501128) and Spain (GQ375158), differences of eight and seven (99\% identity) base pairs, respectively, were evident.

Our phylogenetic analysis using 28S rDNA, placed the Iranian $M$. hispanica population in a clade together with other M. hispanica populations (Fig. 2). 

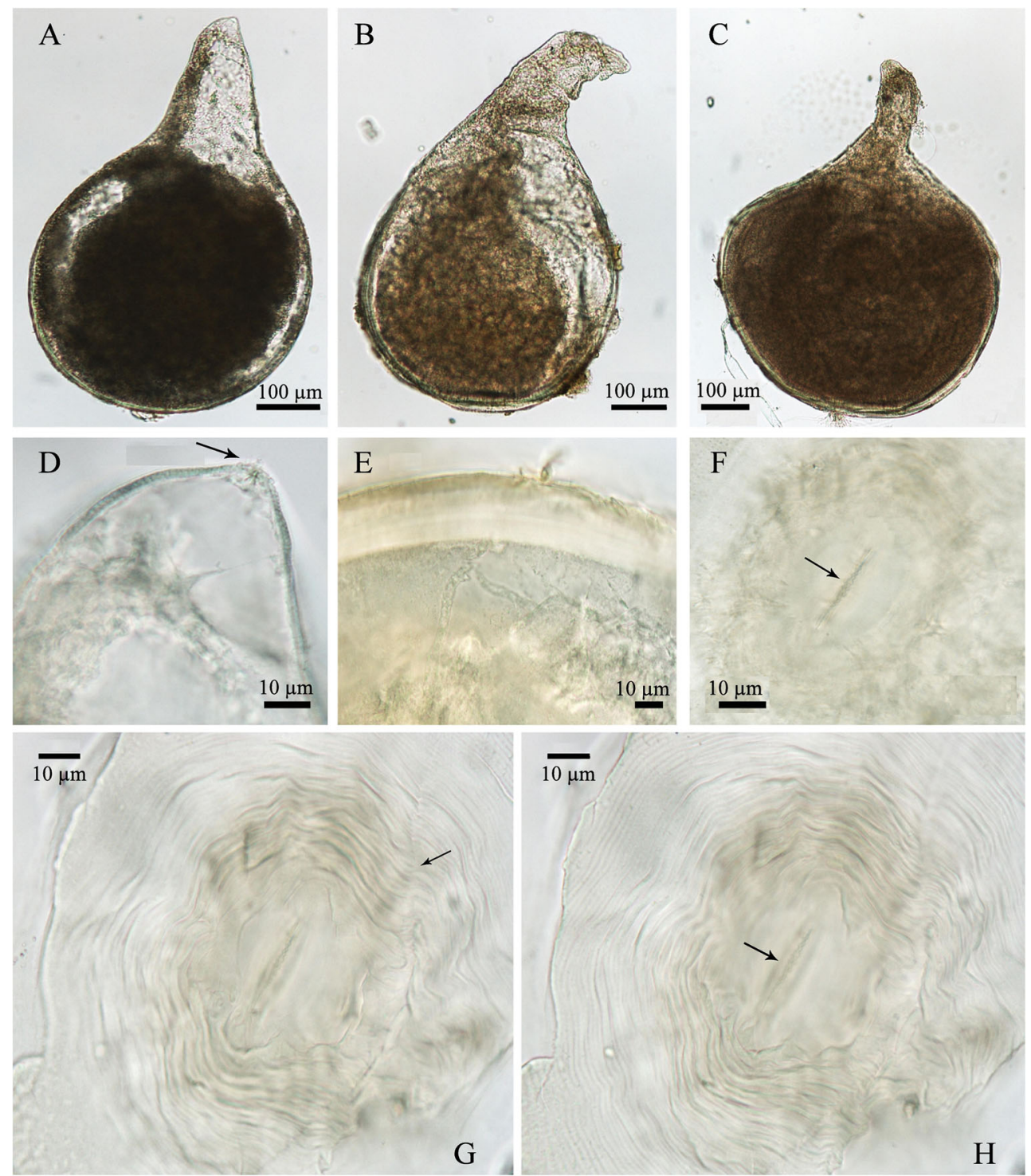

Fig. 1 Meloidogyne hispanica Hirschmann 1986. a-c: Entire female. d: Anterior end of a typical female (arrow indicates lip region). e: Cuticle of a typical female. f: Vulva of a typical female. $\mathbf{g}, \mathbf{h}$ : Perineal patterns of two typical females

Molecularly characterised species of $M$. hispanica thus form a monophyletic group. The phylogeny of Meloidogyne spp. has been studied (De Ley et al. 2002; Tigano et al. 2005) using $18 \mathrm{~S}$ rDNA and $18 \mathrm{~S}$ rDNA and mtDNA, respectively. However, M. hispanica was not included in these studies. Meloidogyne hispanica and $M$. ethiopica are place together in a group, however, they differ in terms of the stylet of the female (small vs large), phasmids (not prominent $v s$ prominent) and lateral line (conspicuous vs not conspicuous). Other genes e.g. mtDNA may separate these two species clearly. Two permanent microscope slides, containing the perennial patterns and females of $M$. hispanica, respectively, were deposited in the National Collection of Nematodes ( $\mathrm{NCN}$ ) at the Nematology Unit, Biosystematics Division, Agricultural Research Council (ARC) - Plant Protection Research Institute (PPRI) (Pretoria, South Africa) with slide numbers 50192 and 50193. According to the literature, this is the first record of M. hispanica in Iran. Morus alba seems to be affected by $M$. hispanica and management practices need to be put in place to control the nematode and to prevent its dispersal to other parks in Tehran. 


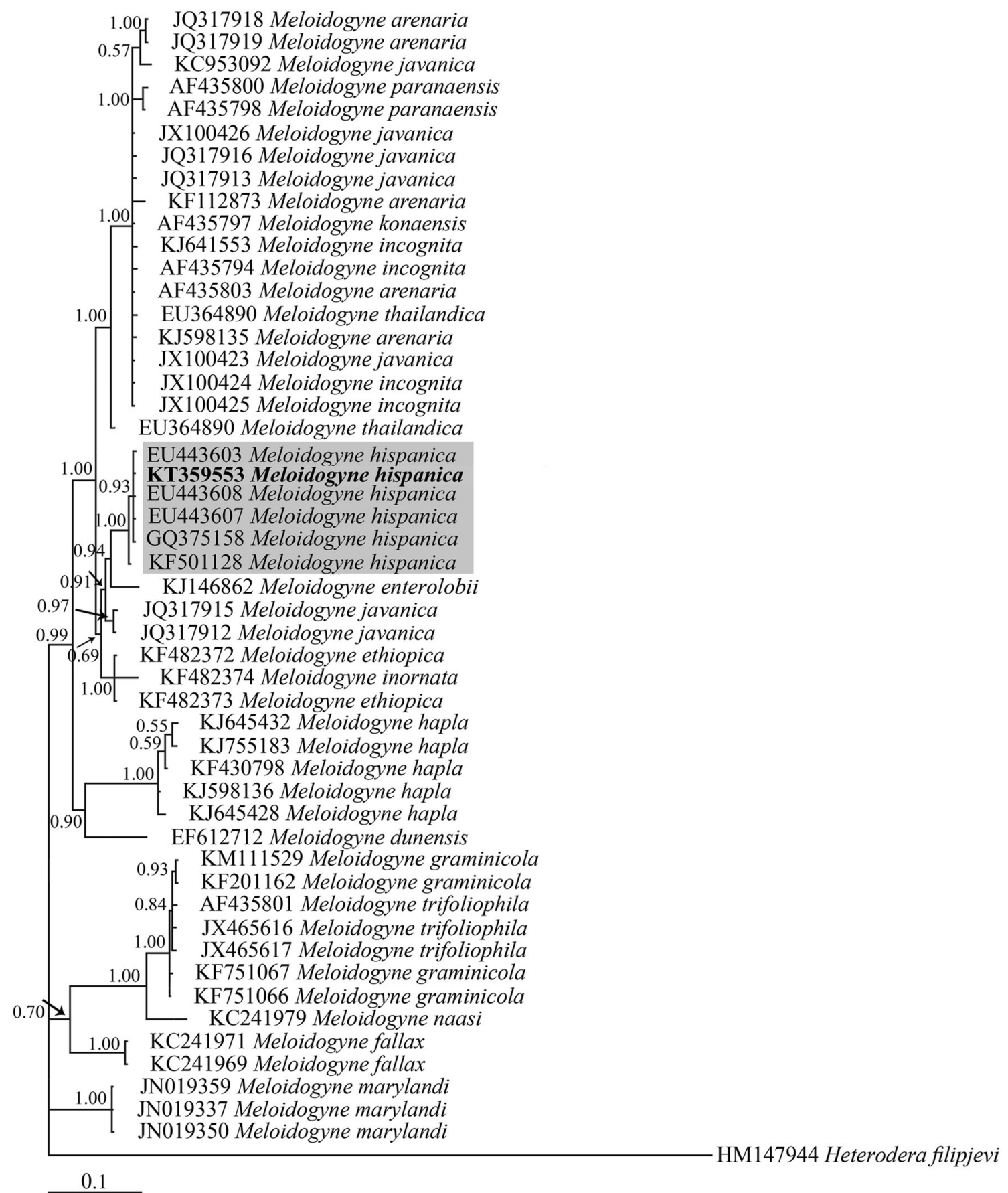

Fig. 2 The Bayesian tree inferred from known and newly sequenced Meloidogyne spp. from Iran based on the 28S rDNA region

\section{References}

De Grisse A (1969) Redescription ou modifications de quelques techniques utililisés dans l'étude des nématodes phytoparasitaires. Meded Rijks Landbouwet Gent 34:351-369

De Ley IT, De Ley P, Vierstraete A, Karssen G, Moens M, Vanfleteren J (2002) Phylogenetic analyses of Meloidogyne small subunit rDNA. J Nematol 34:319-327

Hirschmann H (1986) Meloidogyne hispanica n. sp. (Nematoda: Meloidogynidae), the 'Seville root-knot nematode'. J Nematol 18: $520-532$
Rashidifard M, Shokoohi E, Hoseinipour A, Jamali S (2015) Tylenchulus semipenetrans (Nematoda: Tylenchulidae) on Pomegranate in Iran. Aust Plant Dis Note 10:1-6

Subbotin SA, Sturhan D, Chizhov VN, Vovlas N, Baldwin JG (2006) Phylogenetic analysis of Tylenchida thorne, 1949 as inferred from D2 and D3 expansion fragments of the 28S rRNA gene sequences. Nematology 8:455-474

Suttie JM (2012) "Morus alba L.". Plant production and protection. Food and Agricultural Organization of the United Nations

Tigano MS, Carneiro R, Jeyaprakash A, Dickson DW, Adams BJ (2005) Phylogeny of Meloidogyne spp. based on 18S rDNA and the intergenic region of mitochondrial DNA sequences. Nematology 7:851-862 